\title{
Central line-associated
} the care bundle

\author{
Aynur Atilla ${ }^{1}$, Zahide Doğanay ${ }^{2}$, Hale Kefeli Çelik², Leman Tomak ${ }^{3}$, \\ Özgür Günal ${ }^{1}$, and S. Sırrı Kılıç ${ }^{1}$ \\ Departments of ${ }^{1}$ Infectious Diseases and Clinical Microbiology, ${ }^{2}$ Anesthesiology and Reanimation, Samsun Training \\ and Research Hospital, ${ }^{3}$ Department of Biostatistics, Ondokuzmayis University Faculty of Medicine, Samsun, Turkey
}

Background: The importance and efficacy of a care bundle for preventing central line-associated bloodstream infections (CLABSIs) and infectious complications related to placing a central venous catheter (CVC) in patients in the intensive care unit (ICU).

Methods: A care bundle was implemented from July 2013 to June 2014 in a medical ICU and surgical ICU. Data were divided into three periods: the prior period (July 2012-June 2013), the intervention period (July 2013-June 2014; first and second periods), and the post-intervention period (July 2014-December 2014; third period). A care bundle consisting of optimal hand hygiene, skin antisepsis with chlorhexidine (2\%) allowing the skin to dry, maximal barrier precautions for inserting a catheter (sterile gloves, gown, mask, and drapes), choice of optimal insertion site, prompt catheter removal, and daily evaluation of the need for the CVC was introduced.

Results: The catheterization duration was longer and femoral access was more frequently observed in patients with CLABSIs. CLABSI rates decreased with use of the care bundle. The CLABSI rate in the medical ICU was 6.20/1,000 catheter days during the prior period, 3.88/1,000 catheter days during the intervention period, and 1.05/1,000 catheter days during the third period. The CLABSI rate in the surgical ICU was $8.27 / 1,000,4.60 / 1,000$, and $3.73 / 1,000$ catheter days during these three periods, respectively.

Conclusions: The choice of an optimal catheter insertion site, use of all barrier precautions, and removal of catheters when they are no longer needed are essential to decrease the CLABSI rate.

Key Words: Bundle, CLABSI, Intensive care units, Nosocomial infections.

Corresponding author: Aynur Atilla, M.D.

Department of Infectious Diseases and Clinical Microbiology, Samsun Training and Research Hospital, Samsun, Turkey

Tel: 90-532-5568767, Fax: 90-362-2778569

Email: aynur.atilla@gmail.com

ORCID: http://orcid.org/0000-0001-8027-1991

Received: April 1, 2016.

Revised: April 27, 2016 (1st); May 19, 2016 (2nd); May 24, 2016 (3rd).

Accepted: May 26, 2016.

Korean J Anesthesiol 2016 December 69(6): 599-603 https://doi.org/10.4097/kjae.2016.69.6.599

\section{Introduction}

Central venous catheters (CVCs) are widely used in modern medicine. However, placing a catheter poses infectious and mechanical risks to patients due to complications that can be fatal. Infectious risks include femoral or internal jugular rather than subclavian catheterization; ignoring sterile barrier precautions during catheterization; not using a mask, sterile gown, sterile gloves, and, whenever possible, drapes; and late removal of the catheter. Mechanical factors include ignoring the risk factors of

(c) This is an open-access article distributed under the terms of the Creative Commons Attribution Non-Commercial License (http://creativecommons.org/ licenses/by-nc/4.0/), which permits unrestricted non-commercial use, distribution, and reproduction in any medium, provided the original work is properly cited. 
a difficult catheterization, insertion of the catheter by an inexperienced worker, mechanical complications associated with femoral access, and not using ultrasound guidance during internal jugular catheterization [1].

Attention has been recently directed toward decreasing catheter-related infection rates through regular education programs on how to properly insert a catheter, surveillance studies, and feedback because some reports indicate that these strategies can reduce infection rates in the intensive care unit (ICU) [2]. In this study, we evaluated the efficacy of using a care bundle for preventing infectious complications related to placing a CVC in patients in the ICU and determined whether educational programs are as valuable as reported previously.

\section{Materials and Methods}

In total, 114 patients who had CVCs placed in a 22-bed medical ICU and a 13-bed surgical ICU from July 2013 to June 2014 were enrolled. According to prospective active surveillance data, patients with central line-associated bloodstream infections (CLABSIs) were included in this study. CLABSI was defined as clinical signs of infection, such as culture growth of the same bacteria from blood taken from a peripheral vein, catheter tip, or blood taken from catheter in a patient who did not have a source of infection other than the catheter. CLABSIs were recorded according to the Centers for Disease Control definitions [3]. The care bundle consisted of optimal hand hygiene, skin antisepsis with chlorhexidine (2\%) (without alcohol) and letting the skin dry, maximal barrier precautions while inserting the catheter (sterile gloves, gown, mask, and drapes), choice of optimal insertion site, prompt catheter removal, and daily evaluation of the need for the CVC. Failure to comply with any of the care bundle variables was regarded as total incompliance. Catheters were placed via the subclavian, jugular, and femoral routes. Occasionally, $21 \%$ aqueous povidone-iodine was used for skin antisepsis because of difficulties obtaining $2 \%$ chlorhexidine. The care bundle was checked by a nurse on the Infection Control Committee during the day and by the clinical nurse on the night shift. The catheter insertion sites and drapes were checked daily by these nurses to evaluate infections and complications.

Regular educational programs for healthcare workers and informative meetings in collaboration with anesthesiologists were scheduled during July 2013 to June 2014 (intervention period). Data from the first and second periods (6 months) were analyzed together. These data were compared with those retrieved from the prospective active surveillance data of the Infection Control Committee with written consent of the EPK (Council for Planning of Training and Coordination) at our hospital during July 2012 to June 2013 (prior period). Additionally, 96 patients were on follow-up at the ICU according to the CLABSI rate and compliance with the care bundle checklist during July 2014 to December 2014, and these data were analyzed as the third 6-month period (post-intervention period). No changes in the surveillance protocol or the study team occurred during the study.

Patient data recorded during July 2013 to June 2014 included age, sex, accompanying comorbidities, (diabetes mellitus, chronic renal failure, neurological disease, malignancies, heart failure, chronic obstructive pulmonary disease, etc.), use of total parenteral nutrition, use of blood products, Acute Physiology and Chronic Health Evaluation-II (APACHE-II) score [4], catheter site, catheterization duration, and the care bundle checklist.

The CLABSI rate was calculated as follows: number of CLABSIs / number of central line days) $\times 1,000$, and the CVC duration was calculated as follows: number of central line-days / number of patient days [3].

\section{Statistical analysis}

Statistical analyses were performed with SPSS 18.0 for Windows software (SPSS Inc., Chicago, IL, USA). Data are presented as mean $\pm \mathrm{SD}$, median (range), and frequency (\%). The ShapiroWilk test was used to assess normality of the quantitative data distributions. Non-normally distributed data were analyzed using the Mann-Whitney $U$ test. Frequencies were compared using the chi-square test. The test for two proportions was used to analyze the CLABSI rates. A P value of $<0.05$ was considered significant.

\section{Results}

In total, 114 patients who had a CVC placed were prospectively followed during the intervention period (July 2013-June 2014) in the surgical and medical ICUs, and 27 CLABSIs occurred. Of the 96 patients, CLABSIs developed in 6 patients during the third period.

Among all patients, 60 were male, with a mean age of 67 \pm 21.3 years (median, 73 years; range, $16-100$ years), and the median catheter duration was 12 days (range, 1-65 days). The mean APACHE II score was $24.5 \pm 8.3$ (median, 23; range, 7-43). Hospitalization was due to a neurological cause in $21 \%$ of the patients (acute cerebrovascular disease, subarachnoid hemorrhage), trauma in $15 \%$, cardiovascular disease in $8 \%$ (acute myocardial infarction, cardiac failure), pulmonary disease in 25\% (pneumonia, chronic obstructive pulmonary disease), malignancy in $8 \%$, perforation of the gastrointestinal tract in $12 \%$, and renal failure in $8 \%$. The catheterization duration was significantly longer in patients with a CLABSI $(P=0.018)$, and the frequency of a CLABSI was significantly higher in patients with femoral access than in those with other access routes $(\mathrm{P}=$ 
Table 1. Characteristics of Patients with and without a CLABSI (July 2013-June 2014)

\begin{tabular}{|c|c|c|c|c|}
\hline & $\begin{array}{l}\text { CLABSI }(-) \\
(\mathrm{n}=87)\end{array}$ & $\begin{array}{l}\underset{(\mathrm{CLABI}}{\operatorname{CL}}(+) \\
\end{array}$ & $\begin{array}{c}\text { Total } \\
(\mathrm{n}=114)\end{array}$ & $\mathrm{P}$ value \\
\hline Median age in years & $74(20-100)$ & $71(16-94)$ & $73(16-100)$ & 0.093 \\
\hline $\operatorname{Sex}(M / F)$ & $45 / 42$ & $15 / 12$ & $60 / 54$ & 0.450 \\
\hline Comorbidity & $38(90)$ & $17(81)$ & $55(87)$ & 0.247 \\
\hline APACHE II & $25.3 \pm 8.3$ & $24.9 \pm 8.1$ & $24.5 \pm 8.3$ & 0.841 \\
\hline Compliance with the care bundle & $75(87.2)$ & $15(68.2)$ & $90(83.3)$ & 0.040 \\
\hline Median catheter days & $12(1-65)$ & $22(3-64)$ & $12(1-65)$ & 0.018 \\
\hline Femoral CVC insertion site & $11(14)$ & $9(37.5)$ & $20(20)$ & 0.015 \\
\hline Blood transfusion & $20(27)$ & $10(43.5)$ & $30(31)$ & 0.110 \\
\hline TPN & $30(40.5)$ & $13(54)$ & $43(44)$ & 0.176 \\
\hline
\end{tabular}

Values are expressed as mean \pm SD or number (\%). CLABSI: central line-associated bloodstream infection, APACHE-II: Acute Physiology and Chronic Health Evaluation II, TPN: total parenteral nutrition, SD: standard deviation, CVC: central venous catheter, catheter days: number of catheter days per person.

Table 2. CLABSI Incidence in the Medical and Surgical ICUs

\begin{tabular}{|c|c|c|c|c|c|c|c|c|}
\hline ICU & \multicolumn{2}{|c|}{ Care bundle } & $\begin{array}{l}\text { Patients } \\
\text { (n) }\end{array}$ & Patient days & $\begin{array}{c}\text { Catheter } \\
\text { days }\end{array}$ & $\begin{array}{l}\text { CVC utilization } \\
\text { ratio }\end{array}$ & $\begin{array}{l}\text { CLABSI } \\
\text { rate }\end{array}$ & P value* \\
\hline \multirow[t]{5}{*}{ Medical ICU } & \multicolumn{2}{|l|}{ Prior } & 618 & 7535 & 4680 & 0.62 & 6.20 & \\
\hline & \multirow[t]{3}{*}{ Care bundle } & First period & 436 & 3904 & 1950 & 0.50 & 5.13 & 0.590 \\
\hline & & Second period & 443 & 3887 & 1915 & 0.49 & 2.61 & 0.028 \\
\hline & & $1-12$ months & 879 & 7761 & 3865 & 0.49 & 3.88 & 0.128 \\
\hline & Third period & & 408 & 3760 & 1903 & 0.51 & 1.05 & 0.004 \\
\hline \multirow[t]{5}{*}{ Surgical ICU } & Prior & & 443 & 4486 & 2782 & 0.62 & 8.27 & \\
\hline & \multirow[t]{3}{*}{ Care bundle } & First period & 283 & 2254 & 1295 & 0.57 & 6.95 & 0.647 \\
\hline & & Second period & 307 & 2239 & 1314 & 0.59 & 2.28 & 0.032 \\
\hline & & $1-12$ months & 590 & 4493 & 2609 & 0.58 & 4.60 & 0.091 \\
\hline & Third period & & 340 & 2259 & 1072 & 0.47 & 3.73 & 0.194 \\
\hline
\end{tabular}

ICU: intensive care unit, CLABSI: central line-associated bloodstream infections per 1000 catheter days, Prior: July 2012-June 2013, First period: July 2013-December 2013, Second period: January 2014-June 2014, Third period: July 2014-December 2014. *P values for each period were compared with the value prior to use of the care bundle.

0.015). Chlorhexidine was not superior to povidone-iodine ( $\mathrm{P}$ $=0.095)$. No differences were noted in age, APACHE II score, or the rates of blood transfusion and total parenteral nutrition between patients with and without a CLABSI (Table 1). An 83\% compliance rate was determined for all care bundle practices except chlorhexidine use, and the rate was significantly higher in patients without CLABSIs than in those with CLABSIs $(\mathrm{P}=$ 0.040).

The CLABSI rate in the medical ICU was 6.20/1,000 catheter days during the prior period. This rate decreased to $3.88 / 1,000$ catheter days with use of the care bundle (39\% decrease during the intervention period) and 1.05/1000 catheter days with an $83 \%$ decrease during the third period. The CLABSI rate in the surgical ICU decreased from 8.27 to 4.60 (44.4\% decrease) and to 3.73 (54.9\% decrease) during both periods, respectively. The p-values calculated for each period were compared with the value determined prior to use of the care bundle (Table 2).

\section{Discussion}

CLABSIs are a therapeutic challenge. It is estimated that CLABSIs develop in approximately 200,000 patients annually in the US [5]. Preventive methods such as a CVC care bundle not only reduce patients' risk of mortality but also reduce their ICU length of stay, leading to considerable health resource savings [6]. Studies on this subject have revealed that regular educational programs on antiseptic techniques and catheter placement and maintenance reduce infection rates [7].

We found that the infection rate increased when catheters remained in place longer than needed, when healthcare workers did not follow the care bundle practices, and when the catheter was placed via a femoral route $(\mathrm{P}=0.015)$, whereas no significant relationship was detected between CLABSI and age, sex, or APACHE II scores of the patients. Lorente et al. [8] revealed that femoral venous access is associated with a significantly higher incidence of CLABSI, followed by internal jugular and subcla- 
vian access. In addition, Frasca et al. [9] showed more frequent infectious complications when using femoral or internal jugular access. As indicated by the guidelines, it is essential to remove any intravascular catheter that is no longer needed [10].

Yilmaz et al. [11] reported a $43.4 \%$ decrease in the CLABSI rate, whereas Leblebicioglu et al. [12] revealed a 39\% decrease in a multicenter study. We detected decreases in the CLABSI rates of $39 \%$ and $83 \%$ in the medical ICU during the intervention and third periods, respectively. These rates were $44.4 \%$ and $54.9 \%$ in the surgical ICU for the same periods. We noticed that the CLABSI rate did not decrease significantly during the first 6 months because some difficulties complying with the care bundle practices were detected. However, regular coordination meetings and practice significantly reduced the rates during the second and third periods (Table 2).

Our CLABSI rates were higher than the pooled mean (5.6/1,000 catheter days) in the Turkish National Hospital Infections Surveillance Data, whereas this rate decreased with use of the care bundle. On the other hand, our CLABSI rate, which was 5 to 6 times higher before applying the care bundle, decreased to $1.05 / 1,000$ catheter days during the third period in the medical ICU; this is comparable to the National Healthcare Safety Network rate (2012 medical/surgical ICU pooled mean rate of 1.2/1,000 catheter days; range, $0-3$ ) [13].

McGee and Gould [14] reviewed methods to prevent CVC complications. Other authors have revealed the importance of using antimicrobial-impregnated catheters and inserting catheters into the subclavian vein because the risk of a catheterrelated infection is lower during subclavian catheterization than during internal jugular or femoral catheterization [15]. Using all sterile-barrier precautions while inserting a catheter reduces the rate of infection and costs, and avoiding use of antibiotic ointment prevents an increased rate of fungal colonization [16]. Disinfecting catheter hubs is important because catheter hubs are common contamination sites [17], and removing catheters when they are no longer needed is helpful because the probability of colonization by pathogens is higher, and catheter-related bloodstream infection rates increase over time [18]. Previous reports also described the use of ultrasound guidance and stated that the catheter should be inserted by an experienced worker.

We detected no superiority of chlorhexidine over povidoneiodine for skin antisepsis, but further studies are needed. Chaiyakunapruk et al. [19] compared chlorhexidine and povidoneiodine and concluded that chlorhexidine is more effective for preventing CLABSIs. However, Langgartner et al. [20] revealed that skin disinfection using chlorhexidine and povidone-iodine produces superior results over either regimen alone and concluded that catheter infections can originate from translocating bacteria at the time the catheter is inserted.

In conclusion, selecting the optimal site to insert a catheter, avoiding femoral access, using all barrier precautions, and removing catheters when they are no longer needed are essential to prevent CLABSIs.

\section{Acknowledgments}

The authors gratefully thank the nurses on the Infection Control Committee for their help.

\section{References}

1. Pronovost P, Needham D, Berenholtz S, Sinopoli D, Chu H, Cosgrove S, et al. An intervention to decrease catheter-related bloodstream infections in the ICU. N Engl J Med 2006; 355: 2725-32.

2. Gastmeier P, Geffers C. Prevention of catheter-related bloodstream infections: analysis of studies published between 2002 and 2005. J Hosp Infect 2006; 64: 326-35.

3. Horan TC, Andrus M, Dudeck MA. CDC/NHSN surveillance definition of health care-associated infection and criteria for specific types of infections in the acute care setting. Am J Infect Control 2008; 36: 309-32.

4. Knaus WA, Draper EA, Wagner DP, Zimmerman JE. APACHE II: a severity of disease classification system. Crit Care Med 1985; 13: 81829.

5. Burden AR, Torjman MC, Dy GE, Jaffe JD, Littman JJ, Nawar F, et al. Prevention of central venous catheter-related bloodstream infections: is it time to add simulation training to the prevention bundle? J Clin Anesth 2012; 24: 555-60.

6. Cooper K, Frampton G, Harris P, Jones J, Cooper T, Graves N, et al. Are educational interventions to prevent catheter-related bloodstream infections in intensive care unit cost-effective? J Hosp Infect 2014; 86: 47-52.

7. Eggimann P, Harbarth S, Constantin MN, Touveneau S, Chevrolet JC, Pittet D. Impact of a prevention strategy targeted at vascular-access care on incidence of infections acquired in intensive care. Lancet 2000; 355: 1864-8.

8. Lorente L, Henry C, Martín MM, Jiménez A, Mora ML. Central venous catheter-related infection in a prospective and observational study of 2,595 catheters. Crit Care 2005; 9: R631-5.

9. Frasca D, Dahyot-Fizelier C, Mimoz O. Prevention of central venous catheter-related infection in the intensive care unit. Crit Care 2010; 14: 212

10. O'Grady NP, Alexander M, Burns LA, Dellinger EP, Garland J, Heard SO, et al. Guidelines for the prevention of intravascular catheter- 
related infections. Am J Infect Control 2011; 39(4 Suppl 1): S1-34.

11. Yilmaz G, Caylan R, Aydin K, Topbas M, Koksal I. Effect of education on the rate of and the understanding of risk factors for intravascular catheter-related infections. Infect Control Hosp Epidemiol 2007; 28: 689-94.

12. Leblebicioglu H, Öztürk R, Rosenthal VD, Akan ÖA, Sirmatel F, Ozdemir D, et al. Impact of a multidimensional infection control approach on central line-associated bloodstream infections rates in adult intensive care units of 8 cities of Turkey: findings of the International Nosocomial Infection Control Consortium (INICC). Ann Clin Microbiol Antimicrob 2013; 12 : 10.

13. Dudeck MA, Weiner LM, Allen-Bridson K, Malpiedi PJ, Peterson KD, Pollock DA, et al. National Healthcare Safety Network (NHSN) report, data summary for 2012, Device-associated module. Am J Infect Control 2013; 41: 1148-66.

14. McGee DC, Gould MK. Preventing complications of central venous catheterization. N Engl J Med 2003; 348: 1123-33.

15. Merrer J, De Jonghe B, Golliot F, Lefrant JY, Raffy B, Barre E, et al. Complications of femoral and subclavian venous catheterization in critically ill patients: a randomized controlled trial. JAMA 2001; 286: 700-7.

16. Flowers RH 3rd, Schwenzer KJ, Kopel RF, Fisch MJ, Tucker SI, Farr BM. Efficacy of an attachable subcutaneous cuff for the prevention of intravascular catheter-related infection. A randomized, controlled trial. JAMA 1989; 261: 878-83.

17. Salzman MB, Isenberg HD, Shapiro JF, Lipsitz PJ, Rubin LG. A prospective study of the catheter hub as the portal of entry for microorganisms causing catheter-related sepsis in neonates. J Infect Dis 1993; 167: 487-90.

18. Raad I, Darouiche R, Dupuis J, Abi-Said D, Gabrielli A, Hachem R, et al. Central venous catheters coated with minocycline and rifampin for the prevention of catheter-related colonization and bloodstream infections. A randomized, double-blind trial. The Texas medical center catheter study group. Ann Intern Med 1997; 127: 267-74.

19. Chaiyakunapruk N, Veenstra DL, Lipsky BA, Saint S. Chlorhexidine compared with povidone-iodine solution for vascular catheter-site care: a meta-analysis. Ann Intern Med 2002; 136: 792-801.

20. Langgartner J, Linde HJ, Lehn N, Reng M, Schölmerich J, Glück T. Combined skin disinfection with chlorhexidine/propanol and aqueous povidone-iodine reduces bacterial colonisation of central venous catheters. Intensive Care Med 2004; 30: 1081-8. 